\title{
Design Emocional, Integração Social e Universidade: consideração ao projetar para o idoso contemporâneo.
}

Emotional Design, Social Integration and University: consideration when designing for the contemporary elderly.

BORTOLINI, Hérica; Especialista; Universidade Católica Dom Bosco (UCDB- MS)

herica_mp@hotmail.com

PINA, Fernanda; Doutoranda; Pontifica Universidade Católica do Rio de Janeiro (PUC-Rio)

pina.fernanda@gmail.com

NOGUEIRA, José Francisco Sarmento; Doutor; Universidade Católica Dom Bosco (UCDB-MS)

josefsarmento@gmail.com

\section{Resumo}

Pautado na média de vida da população brasileira, o presente artigo dedica-se atender a crescente população de idosos. Universidades, através de cursos e eventos, procuram integrar esse grupo em seus campus. O PUC-Rio Mais de 50 é uma referência de troca de saberes e de atendimento de demandas desse público, sob a ótica do Design. Inspirado por esta ação, o objetivo é apresentar uma proposta de extensão universitária a ser ofertada em Campo Grande, Mato Grosso do Sul. Para tanto, encontrar formas de integrar socialmente os idosos, por meio de serviços universitários complementou o objetivo. Compreender as razões emocionais de 25 idosos, usuários de atividades promovidas pela Associação Unidos da Feliz Idade em Mato Grosso do Sul, norteou o percurso metodológico. Por fim, o artigo apresenta uma peça gráfica para comunicar a proposta de extensão universitária sul-mato-grossense, considerando suportes teóricos do Design Emocional e a experiência do programa carioca.

Palavras Chave: Design Emocional; dança de salão; Universidade Aberta à Terceira Idade.

\begin{abstract}
Based on the average life of the Brazilian population, this article is dedicated to attending to the growing population of the elderly. Universities, through courses and events, seek to integrate this group into their campus. The PUC-Rio More than 50 is a reference of exchange of knowledges and attendance of demands of this public, from Design's point of view. Inspired by this action, the objective is to present a proposal for university extension to be offered in Campo Grande, Mato Grosso do Sul. To do so, finding ways to socially integrate the elderly through university services complemented the objective. Understanding the emotional reasons of 25 elderly people, users of activities promoted by the United Happy Age Association in Mato Grosso do Sul, guided the methodological course. Finally, the article presents a graphic piece to communicate the proposal of university extension south-mato-grossense, considering theoretical supports of the Emotional Design and the experience of the carioca program.
\end{abstract}

Keywords: Emotion Design; ballroom dancing; Open University for Studies on the Elderly. 


\section{Introdução}

A população mundial está envelhecendo rapidamente. É o que constata um relatório das Nações Unidas. Segundo a entidade, nos últimos 50 anos o número de pessoas mais velhas no mundo triplicou (ONU, 2014). Porém, de nada adianta a conquista da longevidade se o idoso não obtiver realização. O monge beneditino Anselmo Grün (2012), alerta que a sociedade atual precisa ainda encontrar um sentido na velhice e refletir sobre o mistério da condição humana, descobrindo em si próprio se seu envelhecimento será proveitoso. No entanto, a ideia de velhice fortalece a compreensão de uma época sombria, decrépita, repleta de temores da morte, de acometimento de doenças, levando o "velho" ao isolamento social (GRÜN, 2014).

Em consonância com as palavras de Grün, a filósofa francesa Simone Beauvoir (1990), já trazia a tona na década de 70, a significação social do envelhecimento e o papel do velho, com a obra "A velhice". Diante de seus relatos somos apresentados a tribos e grupos sociais e suas formas de lidar com os seus integrantes mais velhos. Percebemos como certos tratamentos, comportamentos, crenças e valores negativos persistem. No entanto, a mesma Simone que apresenta o ser humano ao envelhecer, também revela a proposta da "bela velhice", que ecoa nas palavras da antropóloga Mirian Goldenberg (2013). Para a autora francesa envelhecer bem se resume a "perseguir fins que deem sentido a nossa vida: dedicação aos indivíduos, à coletividade, às causas, trabalho social ou político, intelectual, criador" (BEAUVOIR, 1990, p. 600).

Maria Célia de Abreu, pesquisadora da Psicologia do Envelhecimento, também apresenta exemplos de desprezo que persiste na indiferença e nos maus tratos destinados aos velhos. Em seu livro "Velhice: uma nova paisagem", argumenta que mesmo diante de informações que um velho e um adulto são de mesmo modo importantes para a organização social, podemos, ainda assim, manter sentimentos de desvalorização do velho no ambiente de trabalho, por exemplo. Para a autora, trata-se do clássico "na prática a teoria é outra". Talvez sejam essas as razões pelas quais os rótulos de "velho", "velho inútil" e "velho gagá" perpetuam, cinquenta anos depois do texto de Beauvoir. Como consequência, o comportamento social que exercemos pode estar relacionado à cognição, aos valores e aos sentimentos e emoções (ABREU, 2017).

Afastar-se da ideia de ficar velho, também se justifica através da relação com os impactos sociais que se estabeleceu ao longo da história. Barros \& Castro (2002) destacam que no fim do século XIX e início do XX, o ser envelhecido começa a se relacionar com ideia de "problema social". Os descrevemos como incomodo para a geração vindoura. Os historiadores Lizete Rodrigues e Geraldo Soares, incrementam os estudos sobre a conotação negativa da velhice cultivada pela sociedade. Para eles, o imaginário social do velho está ligado à ideia de estagnação e perdas que levam à ruptura e ao isolamento; inflexibilidade e a valores ultrapassados: a imagem do aposentado improdutivo, significando um final de vida e a falta de capacidade pessoal; pessoa que necessita de cuidados, sem força, sem vontade, sem vida, doente, incapacitado e que por todos esses motivos fez opção pela passividade. (RODRIGUES \& SOARES, 2006, p. 8)

O psicólogo e membro da Unidade de Investigação e Formação sobre Adultos e Idosos da Universidade do Porto, Antônio Fonseca, alerta para importância de criar oportunidades onde idosos exprimam seus sentimentos, se relacionando e criando vínculos de confiança. Acredita-se que assim se minimiza efeitos da solidão, tornando-o mais tratáveis, sociáveis e mais felizes (FONSECA, 2004). Tendo como base esses trabalhos, este artigo buscou implementar medidas para promoção de um envelhecimento ativo, pautado na independência e na vivência em grupo. 
Nesta direção, é reconhecido o trabalho das Universidades para a Terceira Idade, que, no geral, possuem o objetivo de melhorar o bem-estar de idosos na velhice. Segundo os psicólogos portugueses Maria Helena Monteiro e Felix Neto, o movimento das Universidades da Terceira Idade permitiu que este grupo atuasse como cidadãos ativos, recuperando a sua autoestima, revelando à sociedade e aos seus familiares sua capacidade de agirem e lutarem pelos seus direitos de cidadania, tornando-se elementos interventores. (MONTEIRO \& NETO, 2008, p.51)

No Brasil, no entanto, Tiago Ordonez e Meire Cachioni investigaram os motivos que levam idosos a frequentar estas instituições, diagnosticando que eles desejam: aumentar conhecimentos, buscar aperfeiçoamento pessoal, saber mais para ajudar o próximo, aumentar contato social e, por fim, ocupar o tempo livre de forma útil. Para tanto, alertam que as UnATIs devem promover programas mais eficientes, respondendo às reais expectativas de seus frequentadores, provendo conhecimento e atividades que favoreçam a criatividade, expressividade, participação e qualidade de vida (ORDONEZ \& COACHIONI, 2011).

No Rio de Janeiro, a Pontifícia Universidade Católica do Rio de Janeiro (PUC-Rio) tem se destacado na incorporação de atividades de extensão para idosos, sob a ótica do Design. Para universidade é essencial promover atividades com foco no bem-estar dos mais velhos, considerando sua colaboração na geração destas atividades. Tendo como base a experiência realizada pela PUC-Rio, o objetivo deste artigo é analisar e validar o papel do Design Emocional como uma abordagem norteadora para geração de soluções de extensão universitária destinadas ao público idoso. A relevância está na correlação das novas técnicas do Design com as possibilidades de ações universitárias desenvolvidas.

\section{Justificativa}

Para a apresentação e estruturação deste artigo, o projeto buscou inspiração nas práticas do PUC-Rio mais de 50, defendidas pela Professora do Departamento de Artes \& Design da PUCRio, Vera Damazio, atual coordenadora acadêmica do programa. A escolha foi baseada no fato do público com mais de 50 anos não estar sendo bem entendido e atendido pela atual comunicação das ações desenvolvidas, inclusive pelas universidades que se dedicam aos idosos. A inspiração para este artigo se deu quando a autora, que trabalha há dez anos na administração pública e participa de várias ações sociais voltadas para este público, foi submetida ao desafio de fazer um trabalho em grupo na disciplina de Emotion Design no Curso de Especialização "Design Gráfico: Expressão e Cultura" da universidade Católica Dom Bosco, no Mato Grosso do Sul.

\section{Objetivos}

\subsection{Objetivo Geral}

Buscar respostas sociais para os idosos de hoje por meio de ações de comunicação inovadora para produtos e serviços, procurando fugir de estereótipos estabelecidos socialmente.

\subsection{Objetivos Específicos}

- Explorar estudos referentes à velhice e suas demandas contemporâneas.

- Identificar e compreender como se dão práticas das Universidades dedicadas à terceira idade e as práticas do Programa "PUC-RIO mais de 50".

- Explorar os conceitos e práticas do Design Emocional, especialmente no que tange o usuário idoso. 
- Identificar e ajustar uma possibilidade existente de serviço destinado aos idosos, capaz de ser ofertada por uma universidade no Mato Grosso do Sul.

- Investigar as razões emocionais dos usuários idosos de um serviço existente no Mato Grosso do Sul para serem consideradas como um novo serviço universitário.

- Apresentar um ensaio de serviço universitário capaz de atender as demandas emocionais dos idosos, em um ambiente universitário.

\section{Considerações ao projetar atividades extensionistas para o público idoso}

\subsection{A temática da velhice}

Definir o conceito de velhice tem sido um processo pouco consensual, já que se dispõe de vários autores com visões diferentes sobre a temática. A velhice deve ser compreendida em suas múltiplas dimensões, além do conceito genérico-abstrato. Sais (1995), diz que o real significado da palavra remete a pessoas com mais de 60 anos que estão em um determinado período histórico de suas vidas e vivenciam uma relação diferenciada com o mundo. Haddad (1993), em seu trabalho sobre a ideologia da velhice, afirma a homogeneização da compreensão de "uma etapa natural do ciclo biológico da vida, como inexorável da existência a que todos estão virtuais e igualmente expostos". Assim a velhice revela-se um fenômeno inerente ao ser humano.

A etapa da vida caracterizada como velhice, com suas peculiaridades, só pode ser compreendida a partir da relação que se estabelece entre os diferentes aspectos cronológicos, biológicos, psicológicos e sociais. Condições históricas, políticas, econômicas, geográficas, culturais produzem diferentes representações sociais da velhice e também do idoso. Há uma correspondência entre a concepção de velhice presente em uma sociedade e as atitudes frente às pessoas que estão envelhecendo (IRIGARAY e SCHNEIDER, 2008, p. 585).

Vê-se então que como em todas as situações as quais o homem é exposto, a velhice possui uma dimensão existencial em seu processo, onde o modo de pensar e agir são influenciados pelos acontecimentos vividos e intrinsicamente afetados pela interpretação pessoal. Seguindo esta linha de pensamento, o relatório da Organização Mundial da Saúde - OMS (2001) caracterizou a velhice com sendo "o prolongamento e término de um processo representado por um conjunto de modificações fisiológicas e psicológicas ininterruptas à ação do tempo sobre as pessoas". Essa ação do tempo constitui parte fundamental do envelhecimento diante das relações e do sentimento de finitude.

Ainda assim, refletir sobre o envelhecimento e o significado da velhice também estão relacionados à reflexão sobre a vida, em encontrar beleza e aceitação na transformação. De acordo com Grün (2014), é preciso olhar além das alterações físicas e explorar a sabedoria. No progresso atual, a sociedade diminuiu o valor do envelhecer, escrachando a imagem de que o idoso não precisa mais produzir nada. Para o autor é preciso um novo senso de sabedoria. A valorização da pessoa idosa nos força a um olhar positivo do nosso próprio envelhecimento. (GRÜN, 2014, p.8). O idoso, como qualquer indivíduo, precisa sentir que possui valor para a sociedade. É preciso criar formas de inclusão dessas pessoas na comunidade, seja para trocar suas experiências, seja para fugir da solidão que da velhice provoca.

\subsection{Um envelhecimento ativo, saudável e produtivo}

De acordo com a OMS (2005), "envelhecimento ativo é um processo de otimização das 
oportunidades de saúde, participação e segurança, com o objetivo de melhorar a qualidade de vida à medida que as pessoas ficam mais velhas." Ainda é importante salientar que o termo "ativo" está ligado à capacidade de aumentar a expectativa de vida para todas as pessoas. Portanto se faz urgente promover ações, capazes de garantir um bom envelhecimento, devendo este processo ser uma experiência agradável, que inclua desde atividades físicas a atividades profissionais, de forma a contribuir para o bem-estar e permanente sentido de utilidade.

O idoso passa a alcançar uma nova representação a partir do momento em que se encontra como um idoso ativo. "A palavra ativo [também] refere-se à participação contínua nas questões sociais, econômicas, culturais, espirituais e civis, e não somente à capacidade de estar fisicamente ativo ou de fazer parte da força de trabalho" (WHO, 2005, p.13). Goldenberg (2013), por meio de suas pesquisas prevê que estamos diante da possibilidade de "bela velhice", pautada na elaboração e manutenção de projetos de vida. Para tanto, Grün (2014, p.16) alerta que "a sociedade também precisa dar ao idoso o espaço no qual se pode envelhecer bem e dignamente". Esses espaços para a promoção da qualidade de vida, por usa vez, devem trazer repercussões positivas para a saúde, de forma que o envolvimento do idoso em atividades sociais venha a estimular autoconfiança e vínculos que realize e satisfaça os idosos.

Assim, esta etapa da vida deixa de ser vista como déficit vital e social, pois leva a necessidade de reflexão, debate e conscientização da comunidade, bem como do próprio idoso adequando sentimentos, atitudes e comportamentos relacionados à velhice. Simone Beauvoir diz que a velhice deve ser regida pela manutenção da luta por razões de um bem viver: "continuar lutando por objetivos capazes de conferir um sentido a nossa existência [...] desejar prosseguir alimentando na idade avançada paixões suficientemente fortes". (BEAUVOIR, 1990, p.300.)

\subsection{As Universidades Abertas à Terceira Idade}

As Universidades da Terceira Idade são instituições que fornecem respostas sociais e culturais, que criam, dinamizam e organizam atividades de aprendizagem, recreativas e de convívio, por e para maiores de 60 anos. (JACOB, 2008). De acordo com Peixoto (1997), a Universidade da Terceira Idade surgiu no final da década de 60 na França, como um espaço em que se disponibilizavam atividades de sociabilidade para ocupar o tempo livre. Somente em 1980, elas atuariam como conhecemos: um programa educacional, por meio da extensão universitária.

Divulgando tecnologia, história, ciências, artes e várias outras atividades socioculturais, as UnAtis, como ficaram conhecidas, se transformaram em um polo de implementação de serviços que ampliam e desenvolvem relações interpessoais. Segundo Jacob (2012), os objetivos passam também a ser o de fomentar pesquisas sobre temas gerontológicos; integração e a permanência dos idosos nas estruturas sociais, bem como contribuir para o bem-estar e a convivência entre as diversas gerações. Vê-se a oportunidade de diversificar as atividades extensionistas, de ter pessoas que possam apoiar pesquisas científicas no campo da gerontologia e inovação no modelo de ensino dessas instituições, por meio de atividades intergeracionais. Cada uma dessas oportunidades fortalece o tripé que sustenta as universidades: extensão, pesquisa e ensino.

Vislumbra-se também a possibilidade das universidades se tornarem um local onde os idosos recebem assistência e ensino; propiciam uma coorte inestimável para pesquisas em várias áreas do conhecimento, ajudando, assim, na formação de profissionais de alta qualificação e alavancando a produção de conhecimento sobre terceira idade. (VERAS, CALDAS, 2004) 
Portanto, a educação através da universidade, estabelece uma mudança de visão, tanto filosófica quanto pragmática, da real função do idoso na atual sociedade, refletindo sobre sua vida e suas habilidades. Assim, os programas voltados para os frequentadores da Universidade Aberta à Terceira Idade auxiliam na elaboração de um novo objetivo de vida, sendo instrumento de melhoria na qualidade de vida para todos os envolvidos.

\title{
4.4 O Programa de Educação Continuada PUC-Rio mais de $\mathbf{5 0}$
}

O PUC-Rio mais de 50 teve início como um serviço de formação continuada desenvolvido pelo Laboratório de Design Memória e Emoção (LabMemo) do Departamento de Artes \& Design em parceria com a Coordenação Central de Extensão (CCE), ambos da PUC-Rio e com o apoio inicial do extinto Centro de Estudo e Pesquisa do Envelhecimento (CEPE), entidade ligada a Secretaria de Saúde do Governo do Estado do Rio de Janeiro. Mais detalhadamente a professora Vera Damazio explica a essência do programa, em uma entrevista concedida ao jornal da PUC-Rio:

\begin{abstract}
O projeto nasceu de um movimento de designers para entender o que é envelhecer. Começamos a fazer pesquisas de bairro da Gávea, com pessoas acima de 50 anos. Visitamos inúmeras casas, e muitas das demandas que encontrávamos podiam se transformar em designer serviço. Buscamos a parceria com a Central de Extensão da PUCRio para materializar formas de atender as demandas e aporte teórico do Centro de Estudo e Pesquisa do Envelhecimento (Cepe), projeto ligado à Secretaria de Saúde do Estado e ao Instituto Vital Brasil. (DAMÁzIO, 2014)
\end{abstract}

De acordo com Fernanda Pina (2014), colaboradora do programa, por meio da mesma entrevista, o desenvolvimento de novas atividades para pessoas acima de 50 anos veio para aumentar e diversificar o público da extensão universitária da PUC-Rio. "A proposta trouxe novas perspectivas para a educação, conciliando o envelhecimento a novas vivências no ambiente universitário". A Professora Vera Damazio acrescenta, chamando atenção para o fato de que "Envelhecer deve ser algo natural e tratado como positivo" e que deve ser explorado por várias esferas sociais. Alerta que na Europa o processo de envelhecimento se deu vagarosamente, o que permitiu que a sociedade entendesse e atendesse as necessidades desse público. No Brasil, nos últimos 30 anos, o mesmo processo foi rápido e sem a devida adequação social. "Por isso, temos que nos preparar, seja em serviços culturais ou de consumo". (DAMAZIO, 2014)

Como uma das características principais do PUC-Rio mais de 50, se tem a promoção: da sociabilidade, do humor, da cidadania, da identidade, do bem-estar, da autoestima e da necessidade de aprender ao longo da vida. Todas essas características foram apresentadas como atributos do Design Emocional para maiores de 60, que devem ser considerados no ato de projetar para o público sênior, como defenderam Damazio et, al. (2017), depois de uma vivência de quatro anos junto ao programa.

As atividades, portanto, estão agrupadas por eixos temáticos que garantam a aplicação dos atributos citados acima: Arte, Cultura e Entretenimento; Atualidades e Conhecimentos Gerais; Empreendedorismo; Educação Financeira; Cotidiano Digital; Bem-estar e Espiritualidade. O sucesso do PUC-Rio mais de 50 está calcado na mudança de paradigma educacional e diante das novas oportunidades que vão surgindo para o público idoso. O processo deixa de ser centrado no professor e passa a ser centrado no aluno que é incentivado a aprender e a transformar seu próprio cotidiano, fazendo valer sua própria inclusão social. Há um imperativo de que tais mudanças aconteçam gradativamente nas universidades brasileiras e que propostas, como se vê na PUC-Rio, habilitam as competências dos idosos. 


\section{O Design Emocional como abordagem norteadora para atender seniores}

Nos últimos anos vê-se uma crescente preocupação em relação à experiência do usuário com o objeto e a sua interação emocional. O Design Emocional é uma abordagem que busca evocar ou conter reações emocionais, estimulando ou retraindo comportamentos. Os objetos reais e as ideias não são a realidade mais importante para o ser humano. (JÁUREGUI, 2001, P.49).

Jáuregui (2001) ainda expressa que emoções são idênticas em todo o mundo, mas que a maneira de interpretar pode variar. Damazio (2013), nesse sentido, afirma que o design emocional tem o potencial de desencadear reações emocionais a partir de produtos projetados com a percepção baseada em aspectos intangíveis como humor, identidade, sociabilidade, cidadania, bem-estar, solidariedade, cooperação, entre outros aspectos não mecânicos.

De acordo com os estudos de Ceccon (2015), com intuito de idealizar o PUC-Rio mais de 50, os objetivos do Design Emocional incluem identificar as principais emoções evocadas pelo meio físico; entender a razão por trás de conexões afetivas entre pessoas e objetos; desenvolver ferramentas e procedimentos para avaliar as respostas emocionais dos usuários e propor métodos e modelos teóricos para compreender e atender às necessidades emocionais dos usuários e suas vontades que emergem desse processo.

Essas necessidades e vontades se configuram como uma peça chave para o desenvolvimento das soluções de design. Favorecem ambientes e contextos pertinentes para fazer valer as intenções do Design Emocional diante do ato de projetar com foco nas emoções do público que se deseja atender. Donald Norman em "Por que adoramos (ou detestamos) os objetos do dia-a-dia" esclarece a importância das necessidades e vontades usuários, indicando que:

A distinção entre os termos necessidade e vontades é uma forma tradicional de descrever a diferença entre o que é realmente necessário às atividades de uma pessoa (necessidade) versus o que a pessoa quer (vontade). As necessidades são determinadas pela tarefa. [...] As vontades são determinadas pela cultura, pela publicidade, pela maneira como a pessoa vê a si mesma e sua autoimagem. (NORMAN, 2008, p.62, 63).

Norman e também a professora Damazio (2013) apontam ainda para outra premissa do Design Emocional: a tentativa de projetar produtos e/ou serviços que por meio da sua interação com o usuário, seja capaz de evocar memórias e lembranças agradáveis. Segundo a professora, as coisas que fazem bem lembrar se apresentam como uma curiosa classe de artefatos que se destacam por sua capacidade de promover ações, como divertir, enternecer, confortar, fortalecer, encorajar, entre outras de ordem emocional. Assim sendo, há muitos campos do design que tangenciam o ponto da resposta cognitiva de cada pessoa e a sua relação com o produto.

Cabe então aos designers considerarem as emoções dos seus usuários, entendendo que quando se trata de um idoso, o contexto social que se impõe revela seres diversificados e com novas tendências comportamentais, diferentes daquelas que construímos no imaginário social.

\subsection{Associação Unidos da Feliz Idade de São Gabriel do Oeste}

A Associação Unidos da Feliz Idade (AUFI) teve início a partir de um grupo pequeno de pessoas idosas que se reuniam para conversar, tomar chimarrão e se divertir semanalmente. Aos poucos foram surgindo novas ideias e os participantes começaram a organizar eventos com o propósito de arrecadar recursos para comprar materiais, jogos e equipamentos eletrônicos para a animação dos encontros. Com o tempo, surgiu a necessidade de obterem um local para guardá-los 
e também que oferecesse um espaço confortável para os encontros do grupo.

Em 09 de agosto de 2000, AUFI foi fundada em São Gabriel do Oeste, Mato Grosso do Sul, pela Assembleia Geral de Constituição da Associação, com uma sede provisória. Em 10 de Maio de 2002, foi inaugurada a sede própria. Desde a sua fundação a AUFI tem procurado desenvolver projetos que promovam a interação dos idosos por meio de atividades recreativas, visando mantêlos unidos, com vistas a conquistar direitos sociais inerentes a cultura, saúde e entretenimento.

A AUFI atende aos idosos com as atividades de yoga, vôlei, bocha, ginástica, artesanato, baile, jogos e a com a promoção de passeios, geralmente em balneários ou para algum espaço de lazer, para promover a interação e o aumento da qualidade de vida. A cada três meses uma programação especial com palestras informativas, além de cursos especiais, estabeleceu uma parceria com as Secretarias Municipais de Assistência Social e Saúde, onde implantou a AUFI SAÚDE que oferece atendimento de segunda a sexta-feira aos idosos acima de 60 anos. Atualmente são mais de 100 idosos atendidos mensalmente e 300 associados registrados. Nove colaboradores e diversos voluntários auxiliam nas atividades e todo recurso financeiro que a entidade dispõe vem majoritariamente da parceria com o poder público municipal e outra parte da promoção de almoços ou jantares realizados na sede da entidade.

Por isso, pensar em ofertar suas atividades em campus universitário para promover um "ganha-ganha", onde de um lado está a universidade se valendo de um novo público, inovando suas atividades de extensão e incrementando o público do campus. Do outro lado, estarão associações, como a AUFI, que ganham em parceria e eventualmente em incremento de renda, tendo uma instituição que regule e intermedia os processos de adesão nas atividades, ou até mesmo encontrando novos espaços, sem custos, para ampliar seu portfólio de ações.

\subsection{Por que um Curso de Dança de Salão para o público da terceira idade?}

Reconhecer a diversidade do público maduro não nega a necessidade de atenção especial dedicada a eles. Pensar no desenvolvimento e na implantação de atividades de extensão para idosos nas universidades traz grandes desafios. Socializar, incluir e compreender a vitalidade desse público deve ser visto como um estímulo para novos caminhos, frente a uma população que está se tornando cada vez mais idosa, mas não necessariamente mais improdutiva e impotente.

Sensibilizar, fazendo com que assimilem a aprendizagens contínuas, os fazendo perceber seu poder de aprender algo novo e sua capacidade de contribuir para reintegração junto à sociedade. Existe, então, necessidade de que a universidade também esteja preparada para estimular e orientar um novo público. É pertinente que se passe a incluir no plano de metas destas instituições o desafio atrair o público maduro, os distanciando do isolamento. Mostrar o valor e a importância do ensino pode proporcionar bem-estar do idoso, nos levando a possibilidade de fazer emergir uma cultura favorável à sua participação junto ambiente universitário.

Para Grün (2014), os mais velhos seguem procurando caminhos totalmente novos e grupos de pessoas que estejam ali para dar-Ihes a sensação de comunidade, de uma família e é neste aspecto que o trabalho desenvolvido se encaixa, em apresentar uma proposta nova para promover a reinserção de homens e mulheres, em uma faixa etária acima de 50 anos, em um curso que cultive os laços de convivência, novos hábitos e rotinas.

De acordo com Souza (2010), a qualidade de vida pode ser promovida pela participação ativa em grupos de convivência, como na prática de atividade física em grupo. Assim sendo, vê-se 
que realizar atividades como a dança, trazem benefícios e modificam o estilo de vida dos idosos e o sentimento de isolamento, já que a pratica necessita da interação e do treinamento constante. Por isso, cursos de Dança de Salão buscam promover a integração social e cultural, além da promoção da saúde corporal e psicológica.

\begin{abstract}
Em se tratando de pessoas idosas, a vivência de dança pode ocorrer em diversos espaços como clubes, igrejas, domicílios, centro de eventos e outros, de forma espontânea e ou coreografada. A dança é uma atividade física bem aceita pelos idosos, pois favorece os relacionamentos, as recordações pessoais, apresenta uma grande riqueza de gestos e movimentos, contribui para a expressividade e criatividade, além de trazer benefícios para a saúde. (SILVA \& MAZO, 2007).
\end{abstract}

Para este estudo, avaliamos a estrutura de uma atividade consistente e com execução de oficinas de dança nas dependências de um Centro de Convivência no estado de Mato Grosso do Sul. Considerando a replicação do Programa em uma universidade no Mato Grosso do Sul e a definição da atividade a ser ofertada, foram realizadas entrevistas semiestruturadas e a aplicação de questionários à um determinado grupo de idosos, frequentadores de uma associação dedicada aos idosos situada na cidade de São Gabriel do Oeste. Após análise dos questionários evidenciouse que $90 \%$ dos entrevistados buscam a satisfação pessoal através de atividades físicas e artísticas após os 50 anos de idade.

A dança, principal atividade apontada neste caso, favorece a ressignificação pessoal e traz não apenas os ganhos físicos, mas também a abertura de um novo meio de relacionar-se, na alegria do encontro e do prazer através da recreação em um ambiente institucional transformador e revolucionário. Tais constatações vão ao encontro com as observações feitas pela professora Vera Damazio acerca do Design Emocional. Ofertar esta experiência é levar a cidadania ao público de maior idade, promovendo civilidade em prol de um bem coletivo.

\title{
6 O Design e seu poder de atuação diante desse contexto
}

Pensando no poder do Design de gerar soluções e articular esferas sociais com foco no bem-estar do usuário, este artigo desbravou um percurso metodológico de caráter exploratório, valendo-se de uma análise de situação análoga para inovar em propostas de extensão universitária. As contribuições da professora Fernanda Pina, responsável pela disciplina Design Emotion, orientaram as entrevistas com idosos que já frequentavam um centro de convivência em Mato Grosso do Sul, fazendo prevalecer uma abordagem qualitativa, capaz de gerar diretrizes para geração de atividades com foco no bem-estar do público idoso.

O estudo foi realizado na Associação Unidos da Feliz Idade, com encontros mensais, que possibilitaram maior aproximação com as experiências vividas pelos idosos. Essa estratégia foi pensada para compreender as situações e as condições de vida em que se encontravam os idosos que participam de atividades do Centro de Convivência. A pesquisa tornou-se relevante à medida que evidenciou elementos importantes para a elaboração da proposta de curso a ser apresentada.

A pesquisa qualitativa descreve-se como uma ligação dinâmica entre o sujeito e o mundo real, de forma que o ambiente da Associação foi fonte direta de dados na abordagem qualitativa, onde os pesquisadores foram instrumentos chave na relação para melhor captação destes dados (PRODANOV, FREITAS, 2013). Os idosos se mostraram participativos e aparentemente engajados ao responderem de forma prática e objetiva um formulário de pesquisa. Enquanto se dedicavam a escrita para fornecimento de seus dados, conversas com os pesquisadores incrementavam as 
percepções sobre suas motivações e interesses.

\title{
6.1 As Entrevistas com idosos frequentadores da AUFI
}

O grupo analisado foi composto por 25 idosos que participam ativamente das oficinas, atividades físicas e cursos disponíveis na AUFI. O método utilizado buscou descrever, as respostas obtidas após a entrevista, a experiência emocional e a relação tangível para a formação de uma identidade que evoca tranquilidade e bem-estar. $O$ instrumento utilizado foi um questionário composto por 7 questões simples e que buscavam a descrição, por parte dos idosos, do sentimento e do significado da participação na Associação. A entrevista foi de fácil aceitação, sendo 15 dos participantes mulheres e 10 homens. Para o estabelecimento da idade mínima usouse o referido disposto que garante a participação na AUFI, pessoas acima de 60 anos de idade. Por questões éticas, o nome dos participantes serão omitidos no decorrer do artigo, sendo que serão utilizados os seguintes descritivos: idoso (a) $A, B, C(. .$.$) e assim sucessivamente.$

A pergunta "O senhor(a), tem família ou vive sozinho?", teve o objetivo de analisar de fato as condições em que o idoso se encontra na sociedade e discutir o sentimento de isolamento bem como traduzir sua identidade de aceitação com o modo que está vivendo.

\begin{abstract}
Sabe como é filha, nós estamos sozinhos depois de uma certa idade, cada um dos nossos filhos vão para um lado, constroem sua própria família e nós nos tornamos apenas avós. Tem horas que bate o sentimento de que não há mais ninguém pela gente." (Idosa A, 72 anos).

Eu moro com minha companheira, nos conhecemos em um baile e os dois já eram viúvos. Só dá pra dizer que tenho uma vida boa e que os filhos nos visitam sempre." (Idoso B, 65 anos).
\end{abstract}

A pergunta "Como o senhor (a), acha que as pessoas enxergam o idoso hoje?", teve o objetivo de observar, na perspectiva do próprio idoso, como a sociedade está retratando a população em uma faixa etária superior aos 60 anos.

Todo mundo acha que velho é quem anda de muletas. Dá pra ver na tv e também naquelas propagandas de posto de saúde, só nos veem como doentes. (Idosa A, 72 anos).

As pessoas ainda me enxergam como novo. Acho que porque eu sou animado. Mas os idosos hoje são vistos como um estorvo para as pessoas, sempre precisando de remédios pra saúde. (Idoso B, 65 anos).

A pergunta "Faz tempo que o senhor (a) participa das atividades da Associação? O senhor (a) também participa de outros grupos?", foi pensada para obter respostas sobre o engajamento dos idosos em grupos de terceira idade e para compreender a necessidade de participação em atividades que proporcionem o bem-estar.

Eu participo há mais de 6 anos, isso aqui é a minha vida. Não sei o que faria se não fosse o meu grupo de amigos. (Idoso C, 68 anos).

A gente tem a turminha de baralho, a turminha pra assistir futebol, quando a gente se aposenta é o que tem pra gente, né filha? (Idoso D, 65 anos).

A pergunta "O que a Associação representa para você?", teve como propósito investigar a promoção das atividades em grupo como marco simbólico para a qualidade de vida do idoso, sua percepção sobre a própria velhice e a importância do meio em que está inserido.

Eu acho que se a gente não tivesse um lugar para ir muita gente aqui nem existiria mais, sabe? É bom ter um cantinho pra nós ocupar as ideias, falar com as amigas e fazer alguma 
atividade física pra melhorar o corpo. (Idosa E, 71 anos).

Quando eu comecei aqui eu era mais nova, não tinha tanto problemas, agora tô com problema no coração e não consigo participar de tudo. Mas eu não deixo de vir. É minha segunda casa. (Idosa C, 68 anos).

A pergunta "Qual atividade que você mais gosta?", teve como objetivo identificar qual dos "produtos" ofertados pela associação possuíam maior engajamento e era mais atrativo para os idosos do município. Esta pergunta foi fundamental para a proposta original deste artigo.

A dança, o baile, nós amamos dançar. A gente se arruma, vai na frente do espelho e passa maquiagem, fica bonita. Não é porque a gente é velha que não quer mais namorar (risos). (Idosa $\mathrm{E}, 71$ anos).

Acho que todo mundo vai dizer que é o baile da quinta-feira. É a melhor atividade porque nós podemos dançar a tarde toda, só paramos para um lanche bem gostoso que as meninas fazem pra gente. (Idoso F, 70 anos).

É a dança, mas nós queríamos ter curso também sabe, aprender dança de salão, porque aqui nós dançamos no baile e também na dança mais moderna que pra se exercitar. (Idosa $A, 72$ anos)

A última pergunta de caráter exploratório foi "Que outra atividade traria o senhor (a) para dentro da associação? Porquê?", foi pensada para fundamentar a escolha do curso em que a proposta do trabalho foi desenvolvida, identificando as vivências que a pessoa gostaria de viver na velhice, refletindo sobre os estigmas que compõem o envelhecimento ativo do novo idoso.

Na verdade, eu acho que já temos tudo o que precisamos, só queria que aumentassem o nosso espaço aqui. Tem muito idoso e o espaço é pequeno pra dançar. Mas os cursos, eu acredito que podia abrir mais um dia pra dançar (risos). Se nós tivéssemos uma piscina também seria ótimo. Assim poderíamos fazer uma hidroginástica. (Idosa G, 79 anos).

Eu entrei só por causa da dança, eu era pé de valsa quando era mais novo e agora só venho pra dançar. Os amigos ainda jogam bocha, mas eu também acho que devia abrir mais aulas de dança pra gente. (Idoso $\mathrm{H}, 80$ anos).

Muita gente acha que porque somos velhos não fazemos nada, e tem gente que fica com cara feia porque venho aqui pra dançar. Não acho que precisamos de mais cursos porque já temos dança, artesanato, pintura, ioga, que podia abrir mais horários. (Idosa E, 71 anos).

Para finalizar, foi perguntado como o idoso tinha acesso às informações e como o mesmo fazia para buscar novas informações. As respostas analisadas garantem que os idosos buscam a identificação visual através de cartazes, panfletos, jornais (principalmente) e até mesmo mídias sociais para se manter informado.

\subsection{Uma proposta de curso de Dança de Salão, considerando o Design Emocional}

Nas palavras de Vera Damazio (2009), verifica-se que as perspectivas do design emocional para a sociedade, baseiam-se em uma estrita ligação entre as pessoas, as coisas, a memória e a emoção resultando no estímulo para novas experiências:

As coisas são lembradas quando nos distinguem como indivíduo, surpreendem, trazem conforto, estimulam a fazer o bem, fortalecem laços afetivos e quando nos fazem sentir queridos e importantes (...), ou seja, quando o projeto é orientado pelos atributos da memorabilidade e valorização da identidade, humor, bem-estar, cidadania, sociabilidade e autoestima, certamente contribuirá para a construção de um presente memorável e boas coisas para lembrar. (DAMAZIO, 2009, p.13) 
Para antropóloga Miriam Goldenberg (2013), que resgata Beauvoir (1990) no que tange o belo velho, um bom projeto de vida pressupõe o acesso a atividades que fomentem emoções, que por sua vez, ajudem na manutenção de um arcabouço de sentimentos, na esfera particular e coletiva. Annamaria Palácios, professora especialista com publicidade destinada a idosos, incrementa Goldenberg (2013), alertando a necessidade de se comunicar para um público diverso:

Embora no passado, a velhice fosse vista como um último estágio homogêneo da vida, também denominada como morte social, atualmente, tem se revelado como um universo altamente diverso, composto de aposentados precoces, idosos capazes e com vário dos graus e formas de limitação. (PALÁCIOS, 2005, p. 8)

Percebe-se então que a população madura atual antecipa a busca por qualidade de vida, em atividades que como a dança, capazes de proporcionar um envelhecimento bem-sucedido, pautado pela memorabilidade e em atividades físicas e cognitivas em grupos. A oferta da oficina de dança feita pela Associação Unidos da Feliz Idade em São Gabriel do Oeste deu referência que ajudou a compreender como ações desenvolvidas para um público de mesma faixa etária e residente de uma mesma região que se pretendia atuar.

Pode se dizer ainda que a proposta apresentada se concretiza ao analisarmos os dados obtidos e aplicá-los na confecção das peças e na execução de um curso. Vale destacar que o desenvolvimento da proposta vai ao encontro das perspectivas apresentadas por Vera Damazio, Marília Ceccon e Fernanda Pina, em trabalho sobre o design emocional para maiores de 60 anos. Como sugerem as autoras, o design é capaz de afirmar a identidade e autonomia dos idosos; renovar a sociabilidade com produtos e serviços que favorecem a ampliação do círculo de amizades; promover relaxamento e serenidade; além de tornar a rotina mais divertida com oportunidades de entretenimento e descontração. Assim, constatou-se a aplicabilidade das diretrizes que regem o design emocional, vivenciadas através de uma experiência.

A partir da análise de produtos confeccionados para os cursos disponíveis na região, foi desenvolvida uma peça voltada para a exploração em um ambiente universitário. As atuais, utilizadas para a divulgação em cidades do Mato Grosso do Sul, bem como em São Gabriel do Oeste, não evocam o humor, nem despertam a civilidade. No entanto, a realização do curso em si tem como efeito intrínseco em sua mais pura característica o divertimento pessoal, além do bemestar, do sentimento de inclusão e a redução do estresse social.

Ao fim, um dos pontos a ser evocado, é demonstração do prazer e da felicidade, aliados a aumento da autoestima de quem está envelhecendo. A dança é uma ação cognitiva de resgate emocional. Por isso, é importante divulgar e incentivar a prática como forma de manutenção da qualidade de vida do idoso. Através da pesquisa, aqui elucidada, se constatou que a principal fonte de informação desta faixa etária constitui-se essencialmente de anúncios em jornais, revistas, cartazes e Facebook, sendo de características puramente visuais.

Para abordar de forma positiva a realização do curso, foi escolhida imagens de pessoas felizes, o que seria atrativo na busca da atenção desejada. Os cartazes e a arte para Facebook enviadas trazem poucas, mas precisas, informações. Com a divulgação e realização deste curso de extensão, qualquer Universidade poderá amenizar a sensação de solidão do idoso, seu trauma de envelhecer, consequentemente melhorando sua qualidade de vida e aumentando seu prazer de viver, por ainda promover encontros intergeracionais em seu ambiente.

Segundo Kotler (1991), não se consome apenas produtos, mas também a imagem que os 
mesmos transmitem. Daí a necessidade de mudança da imagem que se tem das pessoas na faixa de 60 anos, que vivem em pleno vigor físico e mental. O design, com sua responsabilidade social e como formador de cultura, precisa posicionar-se nesse sentido, promovendo o "novo idoso" para sociedade (NETO, 2011).

De acordo com a Figura 1, uma das confeccionadas, podemos estabelecer um parâmetro onde se traz uma imagem de um casal dançando felizes em meio a outros casais, bem como letras de fácil leitura e compreensão, com poucas e precisas informações.

Figura 1 - Exemplo de cartaz para Curso de Extensão

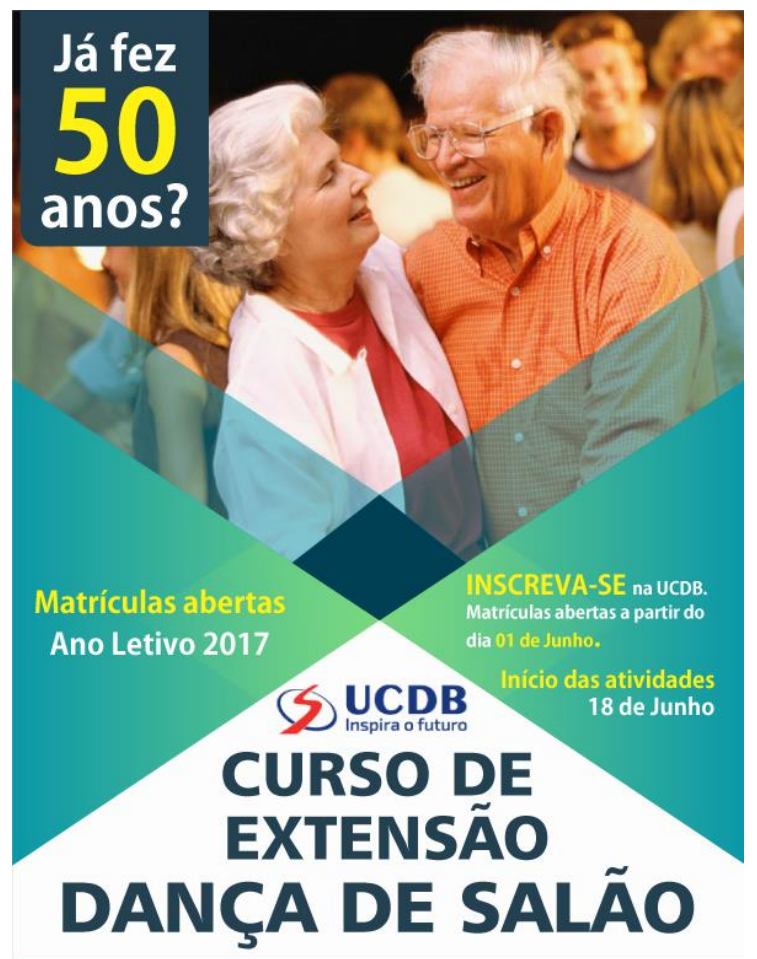

\section{Conclusão}

Mais que inovar as formas de comunicação de produtos e serviços, o artigo constatou que diante da experiência de pesquisa vivida, foi possível reforçar a pertinência dos processos de Design. As atuais propostas difundidas entre outras áreas do saber, relacionadas ao Design Emocional, também confirmam a importância de envolver o usuário final para estruturação e formas de comunicação do serviço que se pretende desenvolver. 0 termo maior de 50, ainda que os serviços fossem destinados aos idosos (maiores de 60), inclui aqueles que se sentem produtivos, ativos e saudáveis, fugindo dos estereótipos acerta do termo idoso, indo ao encontro aos alertas que as teorias aqui exploradas evocavam.

A pesquisa mostrou que a maioria dos idosos está interessada em participar de alguma atividade prazerosa como a dança, que proporciona sentimentos que fazem bem para a qualidade de vida e promovem o humor, sociabilidade e a inclusão social do indivíduo. Nesse sentido, encontra-se a importância de se retratar o idoso de uma nova maneira, trazendo uma nova visão para ele próprio e para a sociedade. 
A pertinência em ajustes na oferta de serviços e na comunicação do mesmo para o público maduro é aumentada e a inovação se estabelece naturalmente. A pertinência se dá pelo fato de comunicar algo para uma parcela da população crescente, apresenta novos comportamentos e preferências como consumidores e que há tempos se mostram insatisfeitos com as mensagens publicitárias destinadas a eles. A inovação emerge do processo de design, por ter nele as premissas de considerar a criação de algo pautado no usuário final, o contexto em que este serviço será ofertado e a criatividade de pensar em novos ambientes, neste caso o ambiente universitário. Entretanto a maior descoberta através deste estudo foi a capacidade que o design traz para criar na memória emoções através da experiência.

\section{Referências}

A, S. (2010). A prática de atividade física pelos idosos do município de Sul Brasil - SC. Santa Catarina: Trabalho de Conclusão de Curso). Departamento de Enfermagem. Centro de Educação Superior do Oeste. Universidade do Oeste de Santa Catariana.

ABREU, M. C. (2017). Velhice. Uma Nova Paisagem. São Paulo - SP: Ágora.

BARROS, R. D., \& Castro, A. M. (2002). Terceira idade: o discurso dos experts e a produção do "novo velho". Estudos interdisciplinares envelhecimento, pp. 113-124.

BEAUVOIR, S. (1990). A Velhice. Rio de Janeiro: Nova Fronteira.

CECCON, M. (2009). Design Emocional: contribuindo para uma nova forma de projetar. Fonte: Relatório PIBIC

CNPq,

2009:

http://www.pucrio.br/pibic/relatorio_resumo2009/relatorio/ctch/art/marilia.pdf.

DAMAZIO, V. (2005). Artefatos de Memória da Vida Cotidiana: um olhar interdisciplinar sobre as coisas que fazem bem lembrar. Rio de Janeiro: Tese de Doutorado em Ciências Sociais na UERJ.

DAMAZIO, V. (2009). Some lessons from memory artifacts of everyday life: toward the design of memorable products. $\quad$ Fonte: IASDR 2009 Proceedings: http://www.iasdr2009.or.kr/Papers/Orally\%20Presented\%20Papers/Behavior/Some\%20Lessons\% 20from\%20Memory\%20Artifacts\%20of\%20Everyday\%20Life\%20-

\%20toward\%20the\%20design\%20of\%20memorable\%20products.pdf

DAMAZIO, V. (2013). Design, memória, emoção: uma investigação para o projeto de produtos memoráveis. Fonte: Cadernos de Estudos Avançados em Design: http://eduemg.uemg.br/arquivos/2013\%20\%20CADERNOS\%20DE\%20ESTUDOS\%20AVANCADOS\%20EM\%20DESIGN\%20\%20EMOCAO\%20(BILINGUI)\%20-\%20VOL.\%208.pdf.

DAMAZIO, V; PINA, F. (2014). PUC Urgente - Entrevista "Educação continuada para maiores de 50 anos". Fonte: Jornal PUC Urgente: http://pucurgente.vrc.pucrio.br/cgi/cgilua.exe/sys/start.htm?infoid=6397\&sid=9

FONSECA, A. M. (2005). Desenvolvimento Humano e Envelhecimento. Lisboa, Portugal: Climepsi Editores.

GOLDENBERG, M. (2013). A bela velhice. Rio de Janeiro: Record.

GRÜN, A. (2014). A Sublime Arte de Envelhecer. Petrópolis - RJ: Vozes.

HADDAD, E. G. (1986). A Ideologia da velhice. São Paulo: Cortez. 
IRIGARAY, T. Q., \& Schineider, R. H. (2008). Participação de idosas em uma universidade da terceira idade: motivos e mudanças ocorridas. Psicologia: Teoria e Pesquisa, pp. 211-216.

JACOB, L. (2008). As universidades seniores em Portugal. Fonte: RUTIS - A Rede que une as universidades seniores: http://rutis.pt/paginas/11/clique-se-quer-serus.

JACOB, L. (2015). A Educação e os Seniores. Revista Kairós, pp. 81-97.

JÁUREGUI, J. A. (2001). Cérebro e emoções: o computador emocional. Lisboa: Dinalivro.

JR, K. R., \& VERAS, R. P. (1995). A terceira idade como questão emergente: aspectos demográficos e sociais. Em K. R. Jr, \& R. P. Veras, Terceira idade: um envelhecimento digno para o cidadão do futuro. Rio de Janeiro - RJ: UNATI: Relume Dumará.

KOTLER, P. (1991). Administração de Marketing: Análise, Planejamento, Implementa o e Controle. São Paulo: Atlas.

MAZO, G. Z., \& Silva, A. H. (2007). Dança para Idosos: uma alternativa para o exercício físico. Cinergis - Revista do Departamento de Educação Física e Saúde do Mestrado em promoção da Saúde da Universidade de Santa Cruz do Sul, pp. 25-32.

MONTEIRO, H., \& Neto, F. (2008). Universidades da Terceira Idade: da solidão aos motivos para a sua frequência. Porto, Portugal: Livpsic.

NETO, M. L. (2011). Design de embalagem: a legibilidade pelo usuário idoso. Fonte: Ambiente DESIGN: http://www.um.pro.br/prod/_pdf/000772.pdf.

NORMAN, D. (2008). Design Emocional: Por que adoramos (ou detestamos) os objetos do dia-adia. Rio de Janeiro: Rocco.

PALÁCIOS, A. d. (2005). Velhice, palavra quase proibida; terceira idade, expressão quase hegemônica: apontamentos sobre $o$ conceito de mudança discursiva na publicidade contemporânea. XX Encontro da Associação Portuguesa de Linguística (pp. 69-86). Lisboa: Actas do XX Encontro da Associação Portuguesa de Linguística.

PEIXOTO, C. (1997). De volta às aulas ou de como ser estudante aos 60 anos. Em R. Veras, Terceira idade: desafios para o terceiro milênio (pp. 41-74). Rio de Janeiro: RelumeDumará/UnATI-UERJ.

PRODANOV, C. C., \& Freitas, E. C. (2013). Metodologia do trabalho científico: métodos e técnicas da pesquisa e do trabalho. Novo Hamburgo: Freevale.

RODRIGUES, L. d., \& Soares, G. A. (2006). Velho, Idoso E Terceira Idade na Sociedade Contemporânea. Revista Ágora, pp. 1-29.

SAIS, A. (1995). Coisas de velho: coisas de vida. São Paulo - SP: Dissertação de Mestrado na PUCSP.

WORLD HEALTH ORGANIZATION. (2005). Envelhecimento ativo: uma política de saúde. Fonte: Biblioteca virtual em Saúde - Ministério da Saúde: http://bvsms.saude.gov.br/bvs/publicacoes/envelhecimento_ativo.pdf 